\title{
Annual performance analysis of heat emission in radiator and underfloor heating systems in the European reference room.
}

\author{
Karl-Villem Võsa ${ }^{1 *}$, Andrea Ferrantelli ${ }^{1}$ and Jarek Kurnitski ${ }^{1,2}$ \\ ${ }^{1}$ Nearly Zero Energy Buildings Research Group, Ehitajate tee 5, 19086 Tallinn, Tallinn University of Technology, Estonia \\ ${ }^{2}$ Aalto University, School of Engineering, Rakentajanaukio 4 A, FI-02150 Espoo, Finland
}

\begin{abstract}
In this paper, we investigate the energy usage and emission efficiency of radiator and underfloor heating systems coupled with ON/OFF and PI controls, by performing annual simulations with the IDA ICE software package. Results from measurements carried out in early 2018 at the nZEB test facility near the Tallinn University of Technology are used to calibrate validated emitter and controller models. The calibrated models are then used to assess the energy performance of the systems in a simulation spanning the whole year, using climate data for Strasbourg in the European reference room. The annual simulation is conducted in a specific room with fixed geometry and boundary conditions.

As a novelty value of the present study, we impose a non-standard control strategy based on maintaining a specified operative temperature within the room. A single-valued performance indicator, in the form of an increased air temperature set-point, is accordingly obtained for each emitter configuration to be used in further calculations of hourly, monthly or annual heating energy usage. Such a temperature increment accounts for imperfect control, air stratification within the room and the additional temperature increase that is required for achieving a desired operative temperature.
\end{abstract}

\section{Introduction}

Accurate measurements and predictions of energy consumption within a building are vital for sustainable and efficient energy management. Within a heating system, this assessment is crucial as heat makes up a large portion of energy consumption within a building, more so in the Nordic climate where the heating period spans a large part of the year $[1,2,3]$. While the behaviour of each individual element is generally well-known, as part of a system the combined effect of different factors can be challenging to quantify. This is also true for heating systems: while specific emitter or controller parameters may be known, when these are coupled with different levels of automation and control strategies the resulting response of the system can be hard to predict accurately $[4,5]$.

The performance assessment of emitter and controller combinations is investigated throughout this paper. The European standard EN 15316 [6] proposes an approach that tries to quantify the effect of different components of the system, e.g. the room air stratification due to the emitter system, the control accuracy of the system due to imperfect control, and the effect of the system on thermal comfort, which is expressed by the operative temperature
$[6,7,8,9]$. This quantification takes the form of additive set-point increments to the initial room air temperature set-point, to account for the additional energy needed to overcome the effects of these components.

This study aims to calculate such set-point increments based on experimental measurements carried out in the nZEB test facility at the Tallinn University of Technology. These measurement results are used to calibrate the facility model in IDA ICE [10]; the relevant parameters are then carried over to the European reference room model for annual simulations. From the energy consumption, the set-point increase is then calculated.

This control strategy is a novelty of this work, and does not conform to any existing standard procedure [6, 11]. Our study contributes to the agenda of the CEN TC 130 standardisation technical committee, aiming to determine the experimental input and model calibration data that are needed by product category specific dynamic simulations of heat emission parameters in the European reference room.

\section{Methods}

In this study, the annual heating energy usage of radiator and underfloor heating (UFH) systems is analysed.

${ }^{*}$ Corresponding author: karl-villem.vosa@taltech.ee 
Specifically, the effects of thermal stratification, operative temperature difference from air temperature and control accuracy are under observation. Experimental measurements carried out at the nZEB test facility near the Tallinn University of Technology in March 2018 are used to calibrate the controller models within the IDA ICE software package. To assess the annual heating energy usage, such calibrated models are then used in a separate annual simulation within the proposed European reference room in ISO/DIS 52031, with Strasbourg's IWEC-2 climate file [11].

We tested the following emitter systems:

- 11-type panel radiators with a size of $300 \times 1200 \mathrm{~mm}$ with a nominal heat output of $307 \mathrm{~W}$ at design flow temperatures of $55 / 45^{\circ} \mathrm{C}$, placed under windows

- Wet installation underfloor heating (UFH) with pePEX piping $(20 \times 2.0 \mathrm{~mm}, 300 \mathrm{~mm}$ intervals $)$ at a depth of $40 \mathrm{~mm}$ in screed, nominal heat output of 55 $\mathrm{W} / \mathrm{m}^{2}$ at design flow temperatures of $34 / 29{ }^{\circ} \mathrm{C}$. The UFH covers the whole floor, and no additional floor covers nor finishing exist on top of the screed.

These emitter types were coupled with ON/OFF- and PI-type controllers for heat output regulation.

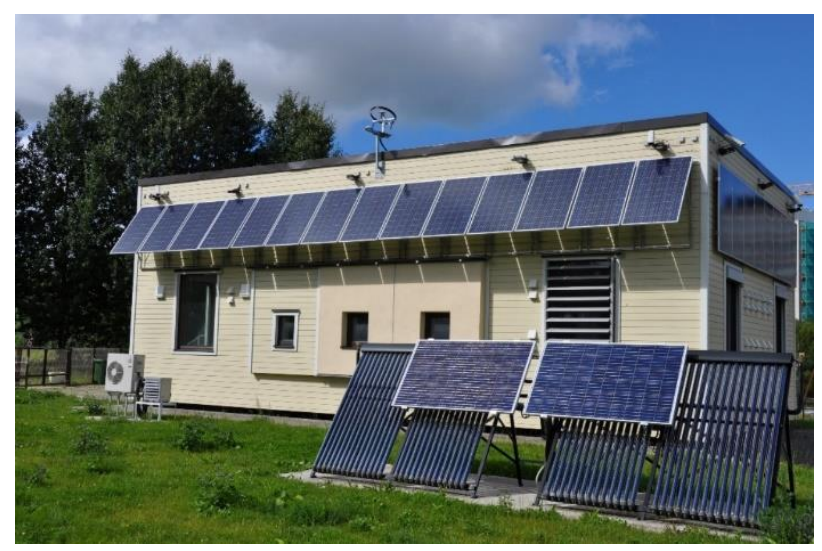

Fig. 1. Tallinn University of Technology nZEB test facility [7].

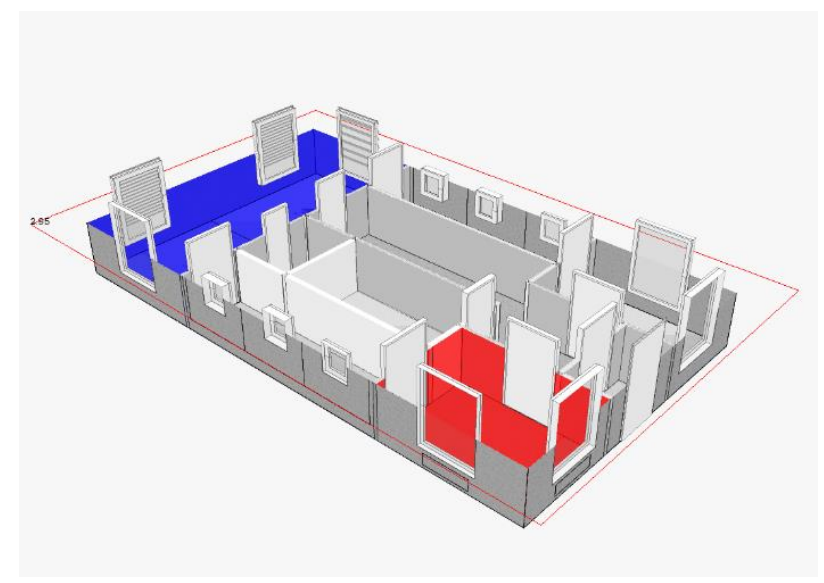

Fig. 2. Measurement room within the nZEB test facility in red.

A residential ventilation air flow rate of $0.71 /\left(\mathrm{sm}^{2}\right)$ was used in all tests $[12,13]$, the rooms were served by a central air handling unit with a supply air temperature of
$18{ }^{\circ} \mathrm{C}$. The set-point for indoor air temperature was $21^{\circ} \mathrm{C}$ in all tests.

Internal heat gains in the form of heating dummy assemblies consisting of a light bulb, fan and metal casing were placed into the test rooms to simulate a more dynamic heat load. The heating load is thus variable, depending on the outdoor conditions and the state of the dummies. This helps better quantify the control accuracy parameters between emitter systems with different thermal mass and control schemes.

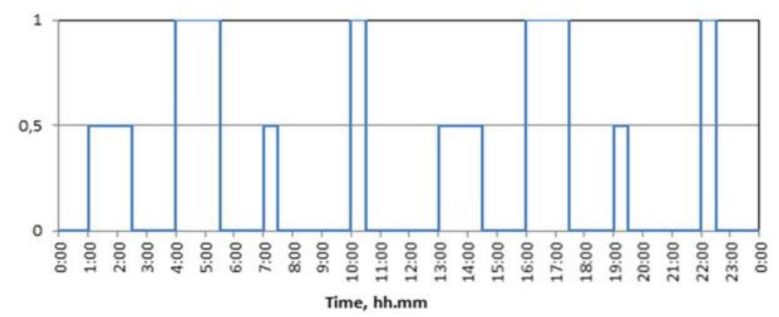

Fig. 3. Heating dummy $24 \mathrm{~h}$ profile, signal of 1 equals to $150 \mathrm{~W}$ heat output.

Over 40 different temperature sensors were installed within the two rooms. Two measurement stands with measurement points at heights $0.10,0.60,1.10,1.70$ and $2.90 \mathrm{~m}$ were placed into each room for vertical temperature distribution measurements, one in the centre of the room and one at $0.6 \mathrm{~m}$ from an external window. All internal and external surfaces were also equipped with a temperature sensor for mean radiant temperature and operative temperature calculations. For a more detailed description of the facility, see [14].
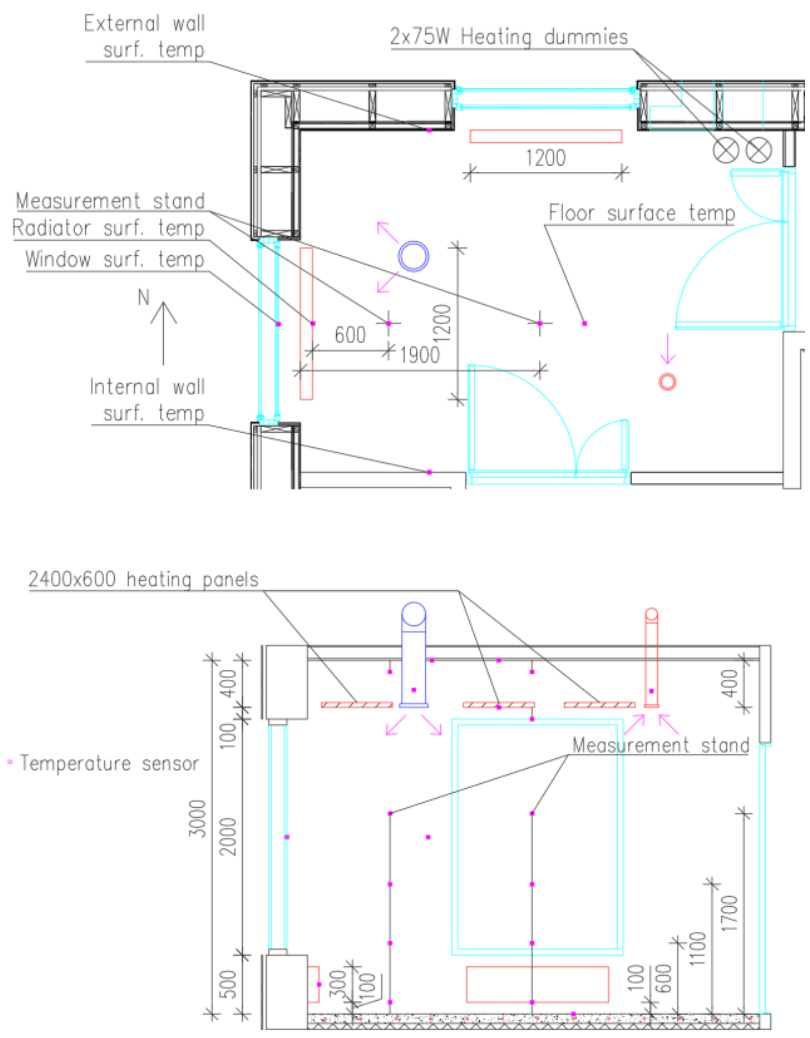

Fig. 4. Plan (above) and section (below) views of the measured room. 
Vertical temperature gradients within the enclosure are calculated from measured air temperatures,

$$
G=\frac{t_{2}-t_{1}}{h},
$$

where $t_{2}$ and $t_{1}$ are the air temperatures at $0.10 \mathrm{~m}$ from the ceiling and floor, respectively, and $h$ is the distance between the two measurement points.

The operative temperature is calculated according to ISO 7726:1998 [15] as the average of surrounding air temperature $t_{a i r}$ and mean radiant temperature $t_{m r t}$ at the point of occupancy,

$$
t_{o p}=\frac{t_{\text {air }}+t_{m r t}}{2} .
$$

The mean radiant temperature is calculated from enclosing surface temperatures,

$$
t_{m r t}=\sqrt[4]{\sum T_{n}^{4} F_{p \rightarrow n}}
$$

where $T_{n}$ is the n-th surface temperature and $F_{p \rightarrow n}$ is the view factor from the $n$-th surface to the point of occupancy. Throughout this paper, the occupant is assumed to be seated in the middle of the room at a height of $0.60 \mathrm{~m}$.

Each emitter and controller combination were measured for 2-5 consecutive days. On-site weather station data including the outdoor air temperature, relative humidity, solar irradiance, wind direction and intensity were used to create a local weather file. For a detailed analysis of the measurement results, see [16].

Measured weather data, along with the measured vertical temperature gradient, were used as input for the IDA ICE calibration simulation. The building model used to simulate the measurement room within IDA ICE is a detailed representation of the nZEB test facility, including both enclosure specification and systems data within the facility. Within this model, a parameter optimisation with GenOpt's Generalized Pattern Search Particle Swarm Optimization with Constriction Coefficient Hooke-Jeeves (GPSPSOCCHJ) algorithm is run [17]. This algorithm combines a stochastic population-based algorithm with a direct search algorithm to decrease the likelihood of becoming trapped near local minima.

The sum of root mean square errors (RMSE) between the measured and simulated air and emitter surface temperatures (front panel surface for radiator, floor temperature for underfloor heating) is used as the objective function,

$$
f(x)=\sqrt{\frac{\sum_{n=1}^{N}\left(\hat{t}_{n}^{\text {air }}-t_{n}^{\text {air }}\right)^{2}}{N}}+\sqrt{\frac{\sum_{n=1}^{N}\left(\hat{t}_{n}^{\text {surf }}-t_{n}^{\text {surf }}\right)^{2}}{N}},
$$

where $\hat{t}^{\text {air }}$ and $t^{\text {air }}$ are the simulated and measured air temperatures, $\hat{t}^{\text {surf }}$ and $t^{\text {surf }}$ are the simulated and measured surface temperatures and $\mathrm{N}$ is the number of measurement observations. This function is then minimized via GenOpt with parameter optimization.

The varied parameters can be separated into two categories:

- measurement parameters

- setpoint temperature variation $\Delta t_{s p}$

$\circ$ measured surf. temperature variation $\Delta t_{\text {surf }}$

$\circ \quad$ internal gain radiation fraction $R F$

- controller parameters

\section{○ deadband width $D B W(\mathrm{ON} / \mathrm{OFF})$ \\ $\circ \quad$ gain $K$ and integration time $T_{i}(\mathrm{PI})$.}

The need for temperature variations arises from possible differences in measured temperatures due to spatial variation within the room and sensor inaccuracy. In the simulations within the room, the air and surfaces temperatures are in fact assumed to be uniformly distributed; including the above variations is therefore mandatory to guarantee an accurate calibration of the model. $R F$ variation in particular is needed to match the temporal delay between the internal gains switching on and off and the indoor air temperature response.

The gain and integration time for the PI-controller are valid for the following representation of the control variable [18]:

$$
u(t)=K e(t)+\frac{K}{T_{i}} \int_{0}^{t} e(\tau) d \tau .
$$

After optimization, the same emitter and calibrated controller models are transferred to two different IDA ICE European reference room models representing new and old building types (see Table 1 and Fig. 5 for the specifications). This reference room has two external walls and one external windows, the rest of the enclosure is considered adiabatic. The internal gains represent the heat emitted from occupants, equipment and lighting and

\begin{tabular}{|c|c|c|}
\hline Building type & \begin{tabular}{|c|} 
New \\
building
\end{tabular} & $\begin{array}{c}\text { Old } \\
\text { building }\end{array}$ \\
\hline Dimensions $\mathrm{x} / \mathrm{y} / \mathrm{z} \mathrm{m}$ & \multicolumn{2}{|c|}{$4 \times 4 \times 3$} \\
\hline Windows area $\mathrm{m}^{2}$ & \multicolumn{2}{|c|}{3} \\
\hline Ext. wall U-value $\mathrm{W} /\left(\mathrm{m}^{2} \mathrm{~K}\right)$ & 0.25 & 0.90 \\
\hline Window U-value $\mathrm{W} /\left(\mathrm{m}^{2} \mathrm{~K}\right)$ & 1.08 & 2.34 \\
\hline Frame U-value $\mathrm{W} /\left(\mathrm{m}^{2} \mathrm{~K}\right)$ & 1.20 & 2.00 \\
\hline Window frame fraction $\%$ & \multicolumn{2}{|c|}{30} \\
\hline Window g-value & 0.64 & 0.76 \\
\hline Air exchange rate $\mathrm{h}^{-1}$ & 1 & 1 \\
\hline Supply air temperature ${ }^{\circ} \mathrm{C}$ & 18 & $t_{\text {out }}$ \\
\hline Heat recovery efficiency & $\begin{array}{c}0.8 \\
\mathrm{t}_{\mathrm{exh}}>0{ }^{\circ} \mathrm{C}\end{array}$ & - \\
\hline Internal gains $\mathrm{W} / \mathrm{m}^{2}$ floor & \multicolumn{2}{|c|}{3.8} \\
\hline Supply/return temp. for $\mathrm{rad} .{ }^{\circ} \mathrm{C}$ & $55 / 45$ & $70 / 55$ \\
\hline Supply/return temp. for $\mathrm{UFH}{ }^{\circ} \mathrm{C}$ & $35 / 28$ & $40 / 30$ \\
\hline Control & \multicolumn{2}{|c|}{$\begin{array}{c}t_{o p}=20{ }^{\circ} \mathrm{C} \text { middle of } \\
\text { room at } \mathrm{h}=0.60 \mathrm{~m}\end{array}$} \\
\hline Gradient $\mathrm{K} / \mathrm{m}$ & \multicolumn{2}{|c|}{ Measured value } \\
\hline
\end{tabular}
are applied within the model with a usage schedule according to EN 16798-1.

Table 1. European reference room specifications according to EN 15316-2 and ISO 52031 (pending). 


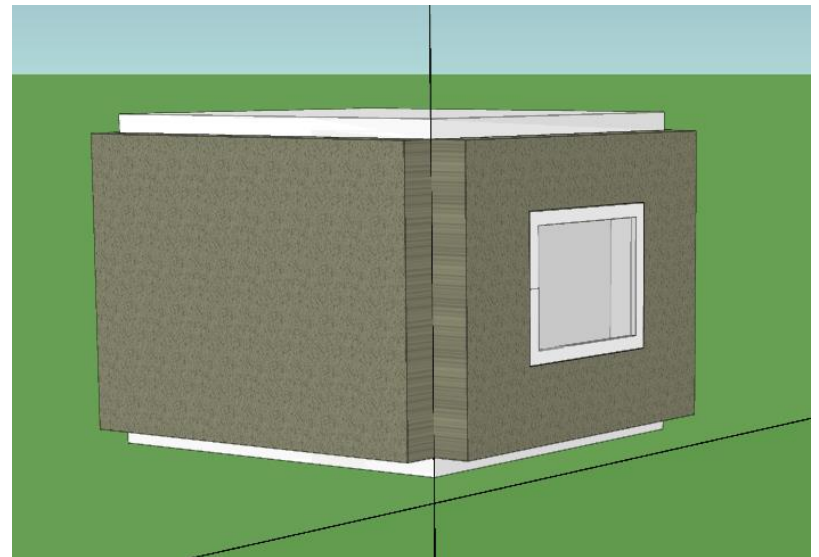

Fig. 5. European reference room geometry with two external walls and adiabatic floor/ceiling.

Annual simulations are run in this model, using the geographical location of Strasbourg along with its corresponding IWEC-2 climate file. The applied vertical gradients within the model are the same as measured in the test facility, 0.13 and $0.04 \mathrm{~K} / \mathrm{m}$ for the radiator and UFH systems respectively. Initially, an air temperature set-point of $20^{\circ} \mathrm{C}$ is applied within the system. However, the reference room specification requires a reference operative temperature to be maintained inside the room. Consequently, we search for the lowest air temperature set-point that maintains at least a $20^{\circ} \mathrm{C}$ operative temperature. Requiring this condition to be met $100 \%$ of the time would be impractical, often resulting in overdimensioning the systems. Instead, we allow the temperature to deviate under the threshold for up to $3 \%$ of the duration of the heating period (60 and $141 \mathrm{~h}$ for the new and old building respectively) as specified by EN 16798-2.

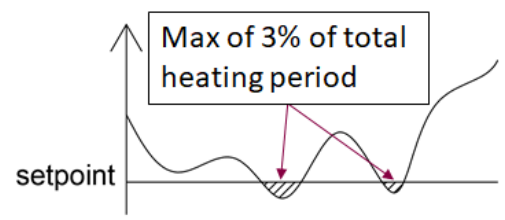

Fig. 6. Allowed deviation of the operative temperature.

The annual heating energy usage at the required setpoint is then compared to the annual heating energy usage of an ideal point heat source, which exhibits no stratification or embedded losses (Fig. 7-Fig. 8). Notice the non-linearity in the case of new building - solar and internal gains have a larger impact on the heating load. From this comparison, to quantify the performance of a certain emitter and controller setup we can compute a setpoint difference. This is similar to the calculation process used in EN 15316-2, where the annual heating energy usage is calculated with an increased temperature [6],

$$
\begin{gathered}
\theta_{\text {int }, \text { inc }}=\theta_{\text {int,ini }}+\Delta \theta_{\text {int,inc }} \\
\Delta \theta_{\text {int,inc }}=\Delta \theta_{\text {str }}+\Delta \theta_{c t r}+\Delta \theta_{\text {rad }}+\Delta \theta_{\text {hydr }}+\Delta \theta_{\text {aut }},
\end{gathered}
$$

where $\Delta \theta_{\text {str }}$ is the spatial temperature variation due to stratification, $\Delta \theta_{\text {ctr }}$ is the control variation, $\Delta \theta_{\text {rad }}$ is the temperature variation due to radiation, $\Delta \theta_{\text {hydr }}$ that due to unbalanced hydronic networks and $\Delta \theta_{\text {aut }}$ is the temperature variation due to space automation of the system. This increased set-point considers the effect of different system components, which may increase energy usage within a system. However, determination of each single component's effect is complicated, as these effects occur simultaneously and it is not possible to measure them individually. Moreover, even if we could measure or calculate each component's value separately, the combined effect would likely not be equal to their sum, as they are not fully independent from each other. For this reason, only a single set-point increment $\Delta \theta$ is calculated based on the annual simulations, and the formula takes the following form:

$$
\theta_{\text {int,inc }}=\theta_{\text {int,ini }}+\Delta \theta \text {. }
$$



Fig. 7. Ideal point heat source annual energy usage at different air temperature set-points in new building.

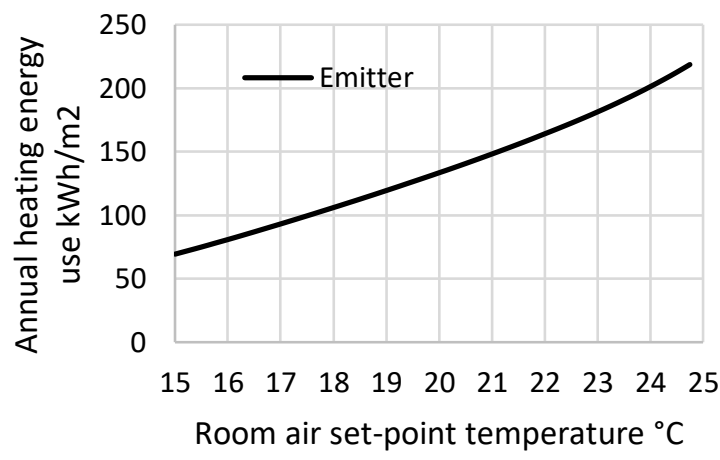

Fig. 8. Ideal point heat source annual energy usage at different air temperature set-points in old building.

Notice that both the energy used to heat up the ventilation supply air and the room are considered for the new building, as they both serve to heat the room under heating load. There also exists a direct link between extract air temperature and AHU heating coil energy usage - higher extract air temperature leads to lower energy usage in the AHU heating coil and vice versa, due to heat recovery. Thus they need to be considered as a sum for an accurate comparison. Fig. 9. 


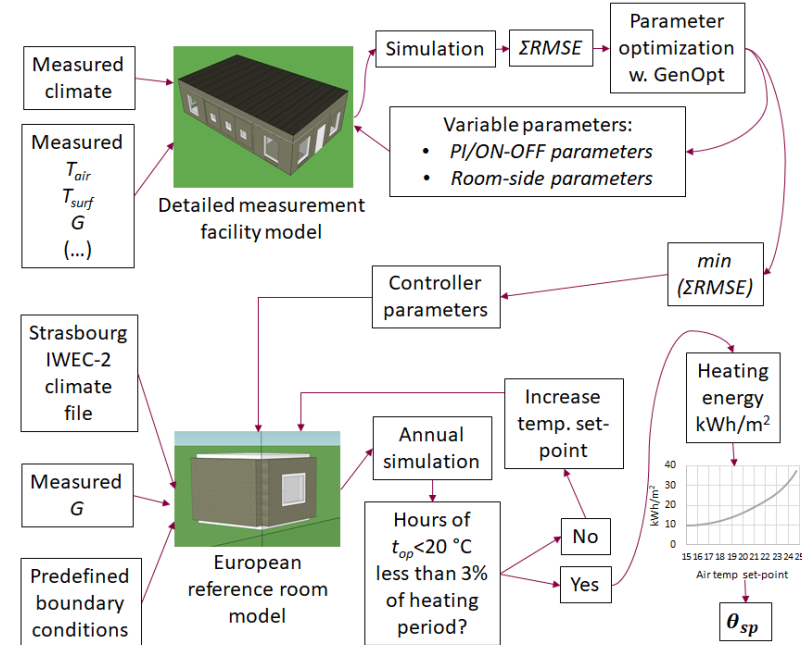

Fig. 9. Workflow of the study.

\section{Results}

Parameter optimization results are shown in Table 2 along with an example of the RMSEs on a minimized solution in Fig. 10. The RMSEs are lower for the UFH, 0.92 and $0.72{ }^{\circ} \mathrm{C}$ for $\mathrm{ON} / \mathrm{OFF}$ and PI control respectively. For radiators, the values are considerably higher, 2.40 and $1.96{ }^{\circ} \mathrm{C}$ respectively, with most of the error rising from the difference in simulated and measured surface temperatures. This is somewhat expected, as the surface temperature changes faster as it has relatively less thermal mass. Accordingly, the amplitude of the variation is also greater and the absolute error is higher. The RMSE of air temperature is considerably lower for PI control. This is also in line with what one would expect, as the amplitude of temperature variation is lower, i.e. the temperature is closer to the set-point. From Fig. 10 it can be observed that for the UFH with ON/OFF control, the air temperature is generally in sync, with occasional mismatches between the measured and simulated scenarios. The values generally quickly converged after diverging, though. Differences in surface temperature are mostly due to temporal offset: there is a time offset between the ON/OFF-action of the controller between the two cases even in the optimized scenario. The controller switching can be clearly distinguished in both the measured and simulated scenarios.

Annual simulation results are presented in Fig. 11-Fig. 15. In Fig. 11, it can be seen that the ON/OFF control requires a higher air temperature set-point to maintain the required operative temperature level, reaching a $+0.71{ }^{\circ} \mathrm{C}$ higher set-point than the PI control. This is an expected result, as temperatures dip under the set-point due to the dead zone between the ON/OFF switching of the controller. This dip is further amplified for the UFH, where the thermal mass of the system delays the heat emission into the room since the layers between the floor surface and piping are heated up first. In Fig. 12 we show the number of hours when $t_{o p}$ is under $20^{\circ} \mathrm{C}$. These are of course all under the threshold, as the air temperature was increased until this very criterion was satisfied.

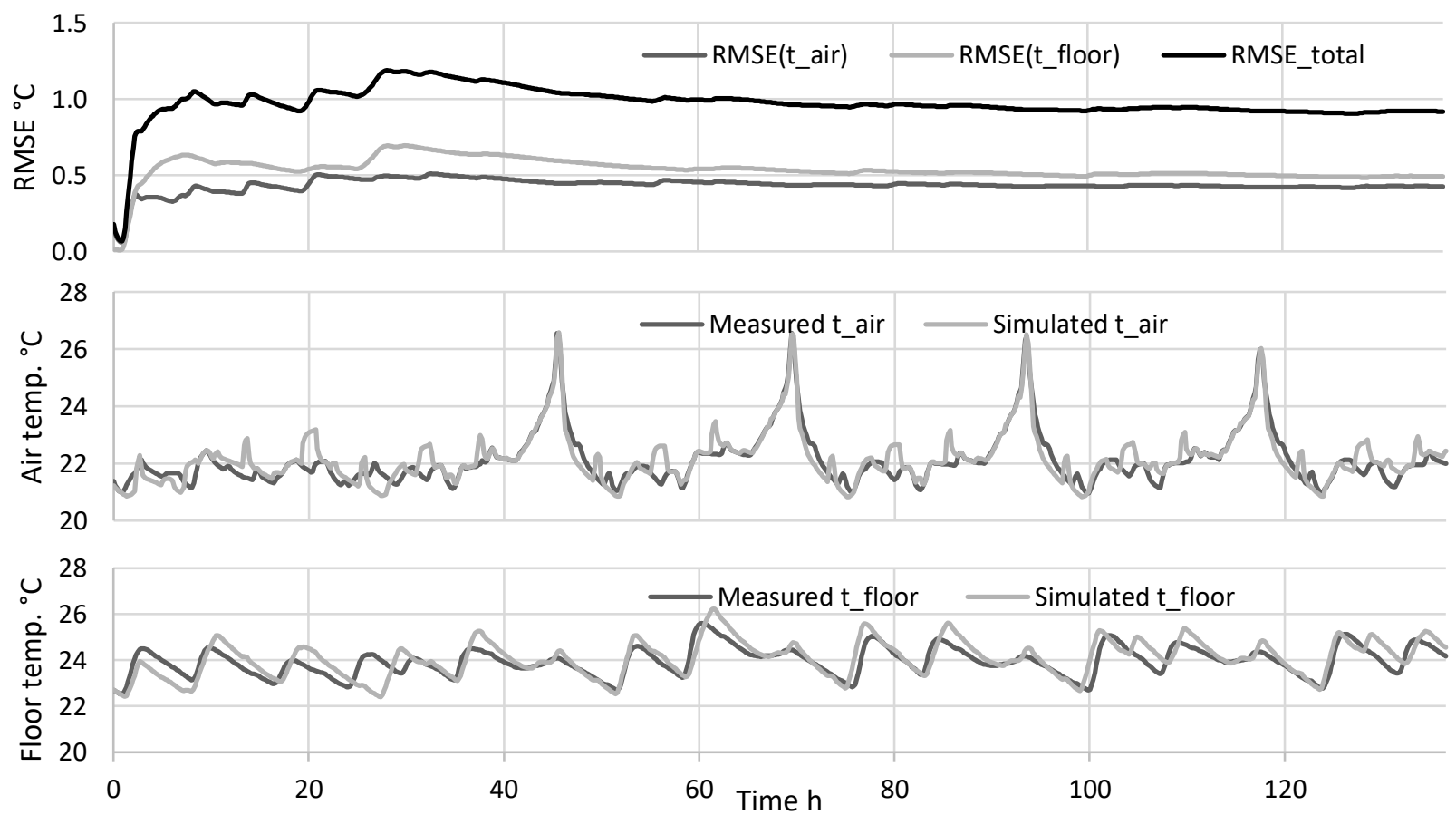

Fig. 10. Minimum RMSE result after optimization for UFH with ON/OFF control. 
Table 2. Parameter optimization results.

\begin{tabular}{|r|c|c|c|c|c|c|c|c|c|}
\hline \multirow{2}{*}{ Emitter type } & \multicolumn{3}{|c|}{ Room-side parameters } & \multicolumn{3}{c|}{ Controller parameters } & \multicolumn{3}{c|}{$\boldsymbol{R M S E}^{\circ} \boldsymbol{C}$} \\
\cline { 2 - 11 } & $\boldsymbol{\Delta t}_{\boldsymbol{s} \boldsymbol{~}{ }^{\circ} \boldsymbol{C}}$ & $\boldsymbol{\Delta t}_{\text {surf }}{ }^{\circ} \boldsymbol{C}$ & $\boldsymbol{R} \boldsymbol{F}$ & $\boldsymbol{D} \boldsymbol{B} \boldsymbol{W}^{\circ} \boldsymbol{C}$ & $\boldsymbol{K}$ & $\boldsymbol{T}_{\boldsymbol{i}} \boldsymbol{s}$ & Air & Surf. & Total \\
\hline Radiator ON/OFF & +0.05 & -2.50 & 0.92 & 0.51 & $\mathrm{x}$ & $\mathrm{x}$ & 0.26 & 2.14 & 2.40 \\
\hline UFH ON/OFF & +0.32 & +0.86 & 0.88 & 0.78 & $\mathrm{x}$ & $\mathrm{x}$ & 0.43 & 0.49 & 0.92 \\
\hline Radiator PI & +0.02 & -1.25 & 0.84 & $\mathrm{x}$ & 2.78 & 1309.00 & 0.18 & 1.78 & 1.96 \\
\hline UFH PI & +0.02 & +0.35 & 0.79 & $\mathrm{x}$ & 3.10 & 820.00 & 0.24 & 0.48 & 0.72 \\
\hline
\end{tabular}

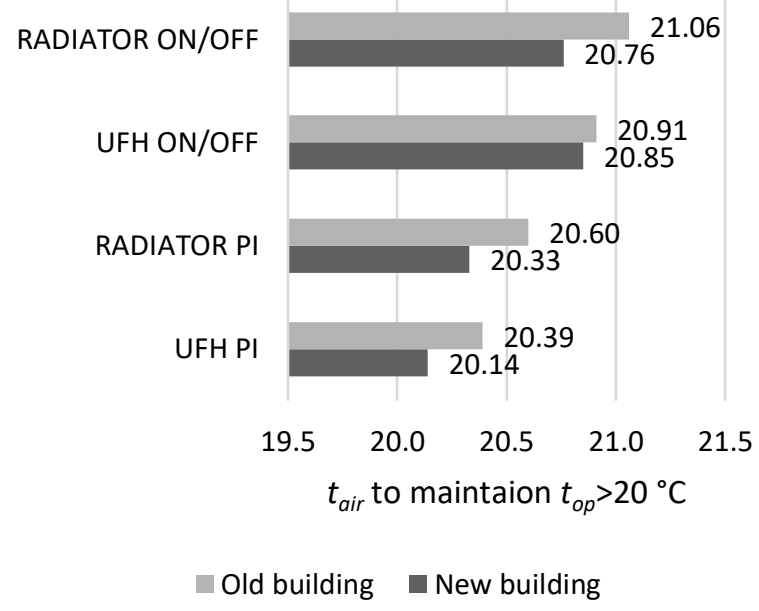

Fig. 11. Required air temperature set-points in annual simulation to achieve $t_{o p}>20{ }^{\circ} \mathrm{C}$ within the allowed deviation.



Fig. 12. Operative temperature deviation under the set-point in the annual simulation results.

In Fig. 13-Fig. 14, the annual heating energy consumption is displayed. For the old building, this is just the energy used by the emitter itself, while for the new building type this is the sum of the energy used within the AHU heating coil and by the emitter. In the old building, the PI control and UFH systems use less heating energy than the ON/OFF control and radiator systems. The difference in energy use can be as high as $9 \mathrm{kWh} / \mathrm{m}^{2}$ or 6 $\%$ between the considered configurations. In the new building, the differences in absolute values are considerably smaller, with a maximum difference of 2.1 $\mathrm{kWh} / \mathrm{m}^{2}$ in the annual heating energy use, or $12 \%$. Only the UFH with PI control shows any considerable difference in energy usage in the new building. Prevalence of UFH in these figures is not accidental when considering how thermal comfort is assessed with the operative temperature - the mean radiant temperature component in the formula benefits from the warm and large floor surface. Furthermore, the warm floor increases the temperature of the other enclosing surfaces as well via radiation, further amplifying the effect. Size is the key here - radiators have a lot higher surface temperatures, but their size is the limiting factor as the view factor to the occupant is not great enough to have enough of an impact on the operative temperature.

In Fig. 15, we illustrate the resulting set-point increase in air temperature to maintain the required operative temperature level inside the room. This increment represents the temperature difference that is needed to overcome additional heating energy use due to imperfect control, stratification of the indoor air and the additional air temperature increase that is required to reach the required operative temperature within the room. Such a temperature increment is meant to be used in monthly, yearly and hourly calculations of heat energy usage with the specified system. As this is calculated from the energy usage in Fig. 13 and Fig. 14 according to Fig. 7 and Fig. $\mathbf{8}$, the qualitative order of the system performance does not change. We observe a maximum difference of $0.63{ }^{\circ} \mathrm{C}$ in the set-point increase between the UFH system with PI control and a radiator with $\mathrm{ON} / \mathrm{OFF}$.

Overall, it was shown that going from experimental measurements to an annual simulation with calibrated models can provide valuable emitter performance data in form of a single-valued parameter to describe its predicted performance. This value can in turn be used in general calculations of annual heating energy use with the specified emitter configuration. 


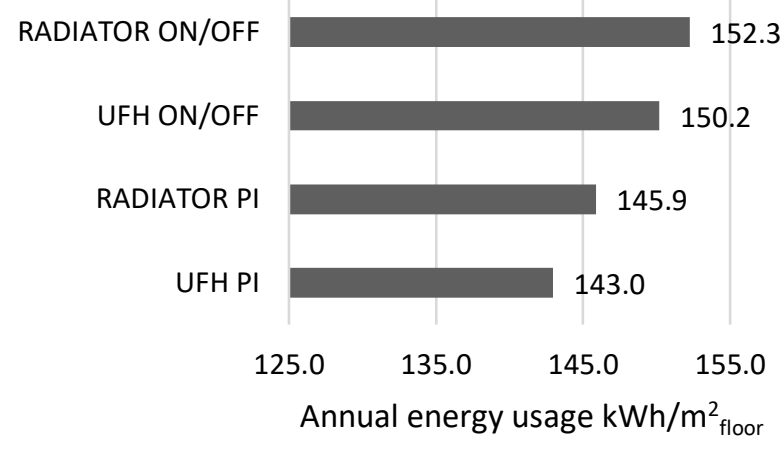

Fig. 13. Annual heating energy usage in the old building.

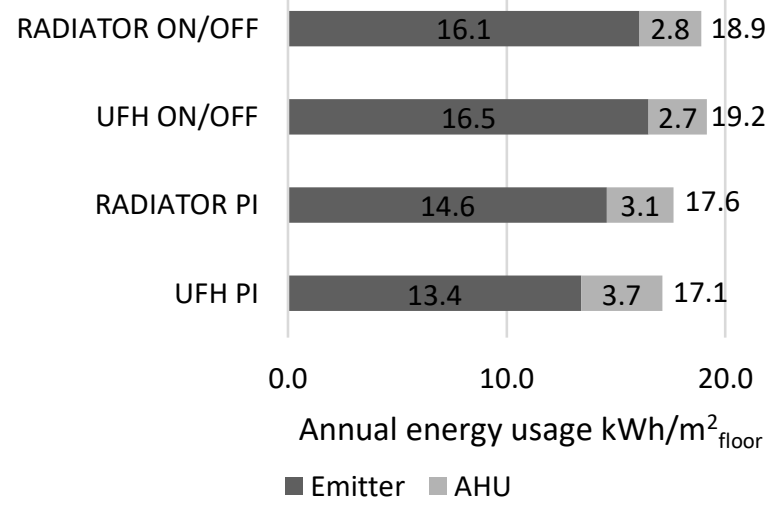

Fig. 14. Annual heating energy usage in the new building.

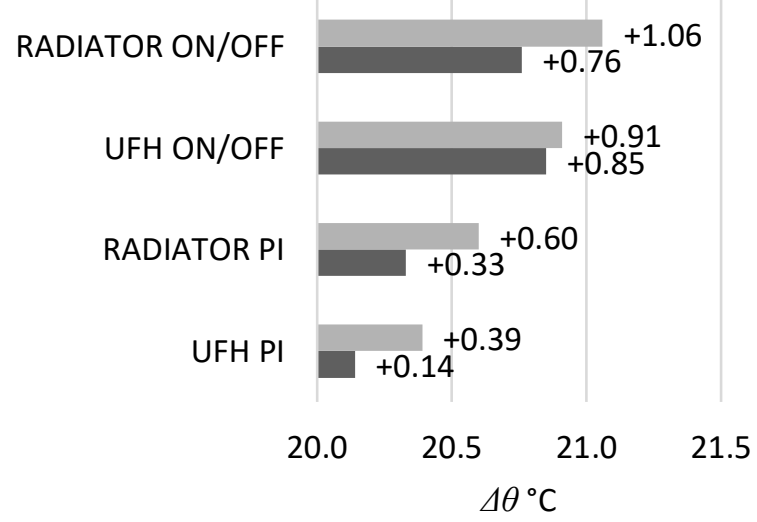

Old building $\square$ New building

Fig. 15. Total set-point increase $\Delta \theta$ for emitter and control system performance assessment.

\section{Conclusions}

In this study, experimental measurements of panel radiators and underfloor heating coupled with ON/OFF and PI control were calibrated in the IDA ICE software package. We performed annual energy use simulations according to a European reference room geometry and boundary conditions, for the climate of Strasbourg. From these simulations, a singular set-point increase was calculated to quantify the performance of the specific emitter setup, with a novel procedure that is not present in actual standards.

UFH systems outperformed the radiators, largely due to the control strategy, which was to maintain a specified operative temperature within the room. The larger warm surface of the floor proved to be more beneficial for establishing thermal comfort within the room than a smaller radiator surface with a higher temperature. Also, the UFH with PI control performed exceptionally well, while the differences between the rest of the configurations were on a smaller scale.

This research was supported by the Association of the European Heating Industry EHI member companies Irsap Spa, REHAU AG + Co, Stelrad Radiator Group Limited, Uponor Corporation, Vasco Group, Wavin B.V., Rettig Austria, Zehnder Group International AG, and Estonian Centre of Excellence in Zero Energy and Resource Efficient Smart Buildings and Districts, ZEBE, grant 2014-2020.4.01.15-0016 funded by the European Regional Development Fund

\section{References}

[1] S. Serrano, D. Ürge-Vorsatz, C. Barreneche, A. Palacios, and L. F. Cabeza, "Heating and cooling energy trends and drivers in Europe," Energy, vol. 119, pp. 425 - 434, (2017).

[2] D. D’Agostino, B. Cuniberti, and P. Bertoldi, "Data on European non-residential buildings," Data in Brief, vol. 14, pp. 759 - 762, (2017).

[3] R. Yao and K. Steemers, "A method of formulating energy load profile for domestic buildings in the UK," Energy and Buildings, vol. 37, no. 6, pp. $663-671$, (2005).

[4] A. Hasan, J. Kurnitski, and K. Jokiranta, "A combined low temperature water heating system consisting of radiators and floor heating," Energy and Buildings, vol. 41, no. 5, pp. $470-479$, (2009).

[5] F. Munaretto, T. Recht, P. Schalbart, and B. Peuportier, "Empirical validation of different internal superficial heat transfer models on a fullscale passive house," Journal of Building Performance Simulation, vol. 0, no. 0, pp. 1-22, (2017).

[6] EN 15316-2:2017, "Energy performance of buildings. Method for calculation of system energy requirements and system efficiencies. Part 2: Space emission systems (heating and cooling), Module M3-5, M4-5,.” CEN, Standard, (2017).

[7] M. Maivel, A. Ferrantelli, and J. Kurnitski, "Experimental determination of radiator, underfloor and air heating emission losses due to stratification and operative temperature variations," Energy and Buildings, vol. 166, pp. $220-228,(2018)$.

[8] B. Lin, Z. Wang, H. Sun, Y. Zhu, and Q. Ouyang, "Evaluation and comparison of thermal comfort of convective and radiant heating terminals in office buildings," Building and Environment, vol. 
106, no. Supplement C, pp. 91 - 102, (2016).

[9] A. H. H. Ali and M. Gaber Morsy, "Energy efficiency and indoor thermal perception: a comparative study between radiant panel and portable convective heaters," Energy Efficiency, vol. 3, no. 4, pp. 283-301, (Nov 2010).

[10] EQUA, "IDA ICE - Indoor Climate and Energy," EQUA, Stockholm, Sweden, Tech. Rep., (2013). http://www.equaonline.com/iceuser/pdf/ice45en g.pdf.

[11] ISO/DIS 52031, "Energy performance of buildings - Method for calculation of system energy requirements and system efficiencies Space emission systems (heating and cooling)," International Organization for Standardization, Standard, (Under development).

[12] EN 15251:2007, "Indoor environmental input parameters for design and assessment of energy performance of buildings addressing indoor air quality, thermal environment, lighting and acoustics," CEN, Standard, (2007).

[13] B. W. Olesen, "Revision of EN 15251: indoor environmental criteria," REHVA Journal, (2012).

[14] M. Maivel, J. Kurnitski, and K. Lahesoo, "Vertical temperature gradient and operative temperature with three heating systems in a lowenergy building," 7. Passivhus Norden / Sustainable Cities and Buildings : Copenhagen, 20-21 August 2015, vol. III, pp. 9-11, (2015).

[15] ISO 7726:1998, "Ergonomics of the thermal environment - Instruments for measuring physical quantities," International Organization for Standardization, Standard, (1998).

[16] K.-V. Võsa, A. Ferrantelli, and J. Kurnitski, "Experimental study of radiator, underfloor, ceiling and air heater systems heat emission performance in TUT nZEB test facility," Slides presentation, Clima 2019, Bucharest, Romania, (2019).

[17] M. Wetter, "Genopt (r), generic optimization program, user manual, version 2.0. 0," (2003).

[18] K. J. Åström and T. Hägglund, PID controllers: theory, design, and tuning. Instrument society of America, vol. 2 (1995). 